\title{
Reference Interviews: Getting Things Right
}

\begin{abstract}
:
Few would disagree that successful communication between librarian and patron is critical to success in the reference process. Based on surgeon/writer Atul Gawande's best-selling book, The Checklist Manifesto, the authors indicate how a well-executed reference interview reflects the structure of a checklist, and how the deeper qualities found in a well-constructed checklist can positively influence the outcome of a complicated interaction.
\end{abstract}

"So - what do you guys talk about in library conferences?" we were asked as we walked across campus with a faculty member after returning from an American Library Association Conference. We replied that, if forced to generalize, we would have to say that the issues discussed at ALA tend to mirror the hot topics outside librarianship - issues such as how to leverage new technologies, how to create innovative, user-centered services, and how to optimally position the profession as we move towards the future. Thinking further about this later, we were impressed by the complexity of the landscape in which we operate. In libraries, as in other realms of modern society, we have at our disposal a great deal of information, but also much uncertainty about how to effectively apply it.

Surgeon and writer Atul Gawande was inspired to think about a parallel problem in his field of study medicine. He was interested in how systems can be designed to operate effectively under conditions of complexity. Medicine, like librarianship, is a field in which practitioners find themselves with the challenge of applying the right information correctly and helpfully.

Gawande's immediate goal was to discover a practical technique aimed at systematically preventing avoidable surgical errors. He began by exploring the error-avoidance practices used in those professions where there is a particularly low tolerance for failure. After talking to professionals as varied as managers of skyscraper building projects to expert pilots, he noticed that effective failure-avoidance systems have in common a simple, low-tech tool that can be widely applied in many different contexts. The tool is a checklist.

\section{The power of checklists}

Gawande's best-selling book, The Checklist Manifesto, tells us more (Gawande 2009). Gawande focused on developing a checklist system aimed at the avoidance of unnecessary surgical mistakes. He found that, despite the skepticism of many doctors, the use of checklists clearly resulted in superior surgical outcomes. Paradoxically, even with the repeated favorable outcomes, it has proven surprisingly difficult to get people to adopt this approach. Perhaps this is because the use of checklists challenges an image that experts typically have of themselves. It requires an attitude of humility that may not be habitual for them. 
Gawande found that when a checklist system is used, it frees specialists to concentrate on the aspects of their work that really require their particular expert judgment. And when the unexpected problem arises, the checklist introduces a calmness, allowing everyone directly involved to trust that the basics are under control, while each is able to focus on his or her unique area of expertise.

On January 15, 2009, Capt. Chesley Burnett "Sully" Sullenberger III and First Officer Jeffrey Skiles began a routine flight from New York to Charlotte, N.C. Both were highly experienced pilots. Sullenberger strapped in with nearly forty years and 19,000 air miles logged; Skiles followed closely behind in both years and miles. Before take-off these two longtime, seasoned pilots ran through their flight checklists.

Flight checklists for the pilot team include not only fact-based routine mechanical and system checks, but also steps in which pilots introduce themselves to one another and to the cabin crew. The checklist calls for the pilots to review the flight plan itself, followed by discussion of any potential concerns, as well as how trouble would be handled if they ran into any - who would do what. The checklist is designed to ensure not only that the plane itself is fit to fly, but also to transform the pilots (who in this case had not flown together before) and crew into a team, prepared to respond together to anything that came their way.

In all of their combined years of piloting, neither man had experienced even a single engine failure. Within minutes after take-off on January 15 their Airbus A320-214 lost both engines to a large flock of Canadian geese that flew into them. Resting upon the engine failure procedures rehearsed in the checklist process Capt. Sullenberger led the pilot team to a successful landing on the Hudson River, saving the lives of all 155 people aboard.

Gawande describes this incident in the Checklist Manifesto because both men were highly experienced pilots and might have easily and understandably skipped over the process of running through the full checklist. Because they did not, Capt. Sullenberger could be certain that Skiles was doing everything possible to re-start the engines, while he focused all of his attention and skill upon the problem of finding a place to land. The pilot and crew's adherence to strict protocols contained in the checklist allowed them to function in a complex and dire situation.

Since the use of checklists seems to provide a useful way to operate effectively in an information rich environment, and has been shown to be successful in avoiding problems in many different professions, we wondered whether checklists could enhance library practice.

\section{The checklist in a reference setting}

Reference is, perhaps, the area of librarianship most analogous to medicine. Both realms involve the provision of direct service to people who have problems in need of solution. In both, you have to act quickly and be as accurate as possible, and you are dealing with a lot of information.

In the early 1980's the Division of Library Development and Services within the Maryland State Department of Education hired several consultants to help them assess reference service performance in public libraries across the Maryland system. The results of the assessment indicated that there was 
much room for improvement indeed, particularly in the area of accuracy (Gers 1985). While there is no substitute for a solid knowledge of available information resources, one of the central skills required for reference success is the effective execution of a reference interview. A system-wide program of reference training was instituted in Maryland to better ensure that library patrons would receive accurate responses more consistently. This was accomplished by training each reference staff member to conduct the reference interview in a similar, proven-effective manner. The training, firmly grounded in the principles reflected in what would later become the RUSA Guidelines for Behavioral Performance of Reference and Information Service Providers was widely adapted and implemented in public and academic libraries throughout the country (American Library Association 2004). Maryland's checklist (Model Reference Behaviors Checklist 1985) demands that each time a reference interview is performed, the reference staff member uses four fairly rigid steps in a particular, proscribed order:

\section{Be approachable}

In person the staff member smiles, makes eye contact, and offers a friendly greeting. Online or over the phone, a friendly greeting is proffered.

\section{Listen/Inquire}

The staff member probes gently using open questions (questions that cannot be answered by 'yes' or 'no') to discover what information is actually being sought. This is done before beginning a search, to avoid wasting valuable time performing inefficient and ineffective steps. If a patron asks for information on mercury some probing is clearly needed to determine whether the search is about the chemical element, the planet, the messenger of the gods in ancient Rome, or an American car.

\section{Clarify and verify:}

The staff member paraphrases the question if necessary to gain a clear understanding of what is needed before beginning a search. A question concerning whether mercury is poisonous seems simple enough but until it is clarified/verified, staff will not know whether to proceed to resources appropriate for a term paper for a nursing class, or whether a speedy referral to a poison hotline is more appropriate.

\section{Follow-up}

Once the information is provided, the staff member ensures the patron actually has the needed information or has sufficient direction to find what he/she needs. To accomplish this staff asks one of the specific recommended 'follow-up' questions. In public libraries this is most often "Did this completely answer your question?" In academic library settings this must be adapted to an environment where teaching also takes place at reference service points. Thus, 'follow-up' in an university library reference transaction (whether in person or virtual) might sound more like "Would you like to try using some of the resources we've discussed and be sure to get back to us as further questions develop?" This is a critical step (and key to reference interview effectiveness) because it alerts the patron that staff cares whether the transaction was successful, and assures the person that library staff members want to persevere if it was not. 
Few would disagree that successful communication between librarian and patron is critical to success in the reference process. However, many academic librarians especially are reluctant to adhere to a checklist consisting of a proscribed set of fairly rigid steps, particularly where the use of the model is incorporated into the evaluation process as an expectation of reference performance. Yet the power of a checklist lies in its very solidity. Think of two buildings, side by side. One is a five-story office building for physicians. The other contains five stories of shops, boutiques, and eateries. Both have the exact same structure - the pillars in each are identical. The pillars are unchanging, consistent, reliable. They are not rigid - they are solid. Yet the buildings look quite different from one another, inside and out. The ways in which individuals make themselves approachable, listen/inquire, clarify/verify, and followup are as varied as the individuals performing the steps.

Checklists, appropriately employed, can help us to navigate complexity more successfully. The consistent, 'rigid'use of the Maryland Model checklist of behaviors can actually become a powerful tool in the provision of excellent reference service. As Dave Tyckoson points out, librarians rarely save lives, but we do shape them on a daily basis, by shaping the experience of our users within our libraries' physical and electronic walls (Tyckoson 2003).

\section{REFERENCES}

American Library Association. June 2004. Guidelines for Behavioral Performance of Reference and Information Service Providers.

http://www.ala.org/ala/mgrps/divs/rusa/resources/guidelines/guidelinesbehavioral.cfm

Accessed January 4, 2011.

Gawande, Atul. The Checklist Manifesto, New York: Henry Holt, 2009.

Gers, Ralph and Lillie Seward. 1985. "Improving Reference Performance: Results of a Statewide Study." Library Journal 110: 32-35.

Model Reference Behaviors Checklist. 1985. http://www.arrowhead.lib.mn.us/more/modelbeh.htm Accessed January 6, 2011.

Tyckoson, David. 2003. "Reference at its Core: The Reference Interview," Reference \& User Services Quarterly 43(1): 49-51. 